\author{
Agnieszka Lawnicka1 ${ }^{1}$, Sławomir Cieśla ${ }^{1}$, Piotr Pluta², Aleksandra Przybylska ${ }^{3}$, Dawid Murawa1,4 \\ ${ }^{1}$ General and Oncological Surgery Clinic of the Karol Marcinkowski University Hospital in Zielona Góra, Poland \\ ${ }^{2}$ Surgical Oncology and Breast Diseases Department of the Polish Mother's Memorial Hospital — Research Institute in Łódź, Poland \\ ${ }^{3}$ Gynecology and Obstetrics Department of the Heart of Jesus Hospital in Środa Wielkopolska, Poland \\ ${ }^{4}$ Surgery and Oncology Department, Faculty of Medicine and Health Sciences of the University of Zielona Góra, Poland
}

\title{
Causes of BIA-ALCL: a summary of the current state of knowledge
}

\author{
Address for correspondence: \\ Lek. Agnieszka Lawnicka \\ General and Oncological Surgery Clinic \\ of the Karol Marcinkowski University \\ Hospital in Zielona Góra, Poland \\ ul. Zyty 26, 65-610 Zielona Góra, Poland \\ phone: 683296368 \\ e-mail: agnese2@vp.pl
}

Oncology in Clinical Practice

DOI: 10.5603/OCP.2021.0013

Copyright (C) 2021 Via Medica

ISSN 2450-1654

e-ISSN 2450-6478

\begin{abstract}
The reasons for the development of breast implant-associated anaplastic large cell lymphoma (BIA-ALCL) have recently been quite a popular topic. The main interest is among plastic surgeons, surgical oncologists, hematologists, and oncologists. Over the past decade, numerous scientific papers on this subject have been published. Potential etiopathogenetic factors include the type of implants, biofilm, inflammation, microtrauma, and genetic mutations. None of the above potential causes have been adequately proven by scientific evidence; anyway, they should not be considered separately, as they are likely to coexist. Further research and exchange of experience among doctors and scientists are necessary to determine the leading etiopathogenetic factor. Its emergence would contribute to the rise of the possibility of using effective preventive measures in patients undergoing breast implant surgery and perhaps even eliminating BIA-ALCL.

Key words: BIA-ALCL etiological factors, breast implants, breast implant-associated anaplastic large cell lymphoma, complications of oncological and plastic surgery

Oncol Clin Pract 2021; 17, 6: 285-290
\end{abstract}

\section{Introduction}

BIA-ALCL, or anaplastic large cell lymphoma, is a rare cancer associated with breast implants. Although it develops within the tissue surrounding the implant, it is not classified as breast cancer [1]. This topic of BIA-ALCL has seen an increase in discussion in the medical community, primarily among oncological surgeons, plastic surgeons, hematologists, and oncologists. The first patient affected by this disease was reported in 1997 [2]. As of April 24, 2020, the American Society of Plastic Surgeons (ASPS) recognizes 903 cases worldwide. The data is based on a global network of international plastic surgery societies [3]. It should be assumed that this data is underestimated due to the lack of sufficient awareness of the problem in the medical world, as well as among patients, and the lack of reporting of each newly detected case to the appropriate, standardized registers. Several theories have been suggested in the etiology of BIA-ALCL - implant surface type, genetic factors, biofilm, inflammatory factors and implant microdamage [4].

\section{Presumptive BIA-ALCL development theories}

Implant surface

We distinguish implants with a smooth or textured surface, as well as - less often - covered with a titanium coating. Each of them has its pros and cons. The benefits of smooth surface implants are the feeling of having a natural breast, increased softness, ease of implantation, and the ability to perform a slightly smaller surgical incision. The disadvantages are greater mobility that can lead to the displacement of the prosthesis, which over time, can lead to stretching of its lower pole. In the case of implants with a textured surface, the benefits are higher resistance to friction and better implant stabili-

Received: 07.06.2020 Accepted: 04.02.2021 Early publication date: 20.04.2021

This article is available in open access under Creative Common Attribution-Non-Commercial-No Derivatives 4.0 International (CC BY-NC-ND 4.0) license, allowing to download articles and share them with others as long as they credit the authors and the publisher, but without permission to change them in any way or use them commercially. 
ty, less risk of capsule contracture around the implant or rotation, and in the case of patients undergoing reconstruction using anatomical implants, the possibility of obtaining a natural upper pole, which reduces wrinkling (especially in prepectoral reconstructions). The relationship between textured surface implants and BIA-ALCL is relatively well established. Cases reported so far have only affected implants with such a surface. Twenty-four cases of incidence regarding patients with smooth surface implants reported to the FDA were not reliable or had a negligible medical history [3]. Collet et al. [5] point to the striking exponential increase in BIA-ALCL incidence in the last decade, which can largely be explained by the increasingly specific implant subtypes. Implants with a large surface and texture (class 4 surface) carry the highest risk of BIA-ALCL. The texture of Allergan implants is referred to as macrotexture. Its role was to reduce the risk of capsular contracture and minimize implant rotation. Countries that have provided confirmed statistics on BIA-ALCL cases, such as the United States, France, and Australia, reported that patients had just implanted macrotextured implants in most reported cases [6]. In July 2018, Egypt introduced a ban on the use of textured implants, while, as of November 21, 2018, the French National Agency for the Safety of Drugs and Medical Products (ANSM) recommends smooth implants. On December 19, 2018, CE certification was not renewed for Allergan Biocell and Microcell implants. On December 21, 2018, Brazil stopped selling Allergan Biocell. On February 7, 2019, Colombia suspended the sale of the same implants. Then, on February 2019, France conducted an ANSM hearing on the implants. On 25/26 March 2019, the hearing is conducted by the US Food and Drug Administration (FDA). In April 2019, France suspended the sale of macro-textured implants. On May 2, 2019, the FDA stated that Allergan does not meet the requirements for implants. In May 2019, Singapore and Canada prohibited the use of Allergan Biocell implants, and in November 2019, Australia prohibits the use of textured implants. On July 24, 2019, the FDA requested the voluntary withdrawal of Allergan Biocell implants and tissue expanders. Subsequently, the company withdrew from sales around the world. The FDA's request to Allergan was motivated by the increased risk of anaplastic large cell lymphoma associated with breast implants (BIA-ALCL). FDA investigation showed that the risk of BIA-ALCL associated with Allergan Biocell textured implants is about six times greater than the risk of BIA-ALCL associated with textured implants from other manufacturers. Further distribution of Allergan's textured Biocell implants would likely have serious adverse health consequences. Of the 573 reported BIA-ALCL cases worldwide, 481 patients had Allergan breast implants at the time of diagnosis.
The Allergan Natrelle 133 and 133 Plus tissue expanders have not yet been associated with BIA-ALCL, yet they both have the same Biocell texture. Although tissue expanders are indicated for use for only six months, there is currently no information on how long of an exposure to Biocell texture can induce BIA-ALCL [7]. In turn, the type of surface used in Mentor textured implants is called Siltex. The coating of these implants has a rough surface that prevents the scar from growing around the implant. During the FDA Advisory Committee Meeting in March 2019 [8], it was stated that Mentor's Siltex texture is responsible for 1 case of BIA-ALCL out of 86,029 implants, while Allergan/Biocell for 1 case out of 3,345 implants, and Silimed's polyurethane implants 1 case our of 2,832 implants. The authors suggest that implants with a larger surface area, i.e., textured ones, give a higher chance of bacterial growth, which, when reaching a certain threshold, causes continuous immune activation, which leads to the development of lymphoma. After analyzing the above data, it can be presumed that the technology of implant production (Siltex vs. Biocell) may also play a role when it comes to the development of BIA-ALCL. The Brazilian company Silimed began the production of silicone breast implants covered with polyurethane foam in 1989. In 2008, the German company Polytech started producing its polyurethane implants, before selling implants in Europe under the name "Polytech Silimed" [9]. Both companies implants are covered with the same foam. However, differences in production quality were identified [10], which may explain the differences in the incidence of BIA-ALCL — in Australia, 23 cases related to Silimed implants, and a case related to Polytech implants [11] .

\section{Genetic factors}

Genetic factors are thought to play an essential role in the pathogenesis of BIA-ALCL.

In a groundbreaking study by Blombery et al., mutations in the JAK-STAT3 pathway have been described for the first time [12]. The JAK-STAT3 pathway is the principal intracellular signaling pathway. Pathway abnormalities can be associated with a variety of disease entities - not just cancer [13]. It has been shown that improper activation of this path can trigger malignant transformation and contribute to the development of lymphomas [14]. Oishi et al. [15] in their work also showed that the JAK-STAT3 pathway is constitutively activated in BIA-ALCL, which in some cases is associated with recurrent JAK1 and/or STAT3 somatic mutations. These activating mutations, which may be parallel, were identified in 13\% (3/23) and 26\% (6/23) of BIA-ALCL, respectively. Other genetic changes include DNMT3A and TP53 point mutations. The ideal situation would be if every patient planned to undergo 
implant surgery underwent genetic testing; however, due to the non-specificity of the above mutations, such action would not translate into its justification.

\section{Biofilm}

The biofilm may be a factor initiating the development of BIA-ALCL. The bacteria and the patient's tissue cells compete with each other on the surface of the implant from the moment it is inserted into the body. In 1987, Gristin described it as "race for the surface" [16]. The process of bacterial biofilm formation on the abiotic surface takes place in four phases: initial adhesion, permanent adhesion, maturation and dispersion $[17,18]$. It is now believed that the pathomechanism of the development of peri-implant infection is complex and depends on the properties of the material forming the implant, bacterial virulence factors and the patient's condition $[19,20]$. Among the features related to the surface of the material, the most important are the physicochemical properties and any unevenness formed during the material production stage (surface topography), favoring cell adhesion [21]. Textured breast implants carry a higher bacterial load than smooth implants [22]. The relationship between bacterial biofilm and Tymphocyte hyperplasia has been demonstrated in the pig and human model [23]. Chronic infection associated with breast biofilm is associated with $\mathrm{T}$ cell infiltration [22, 23]. After analyzing 26 breast implant samples in BIA-ALCL patients for biofilm and comparing them with 62 implant pouches in healthy patients, $\mathrm{Hu} \mathrm{H}$. et al. [24] found significant differences between the two groups. A higher percentage of Ralstonia spp. was detected in samples from patients with BIA-ALCL compared to patients without an implant. In contrast, the latter predominated over Staphylococcus spp. They considered that the detection of the microbiome in ALCL samples associated with the breast implant indicates a possible infectious cause. Because breast implants are widely used in both reconstructive and aesthetic surgery, strategies to reduce their contamination should be more widely studied and practiced. However, patients affected by BIA-ALCL do not appear to have a specific microbiome.

It is unclear how the microbiome might change for a patient with previous breast procedures and what role the surgery itself may play in manipulating the microenvironment [25]. Ralstonia spp. is also detected in patients without lymphoma [26]. Ralstonia spp. are nonfermenting Gram-negative bacilli found in soil and water. Ralstonia spp. have been reported in nosocomial infections resulting from contamination of medical solutions (e.g., water for injections, aqueous chlorhexidine solution) and are being increasingly recognized as a pathogen causing serious soft-tissue and implant-related infections [27-29].

\section{Inflammatory theory}

Chronic inflammatory processes are a known etiological factor in the development of cancer [30]. The relationship between some lymphoma subtypes and infectious agents has been demonstrated in many clinical studies and epidemiological observations. Due to the increasingly better access to advanced molecular techniques, the amount of detected infectious agents associated with the development of lymphomas may increase [31]. In turn, the presence of a foreign body such as a breast implant can cause local, chronic inflammation. Such suggestions are made in a paper published, among others, by Marshall et al. [32] in essence, it was found that the capsule around the implant presented features of chronic inflammation, including fibrosis, plasma cell hyperplasia, and lymphocytic infiltrates. Bizjak M. et al. [33] suggest in their work that patients with an inflammatory response to silicone implants should be closely monitored. They believe that implants - especially those used in the past - can cause chronic stimulation of the immune system against artificial material. As for implants covered with polyurethane foam, according to the paper by Handel N. [34], it stimulates the creation of a unique scar tissue that histologically differs from a tissue around smooth or textured implants. Non-polyurethane implants induce a relatively short-lived, sterile, and cell-free inflammatory response. According to the authors, polyurethane implants have a measurable advantage over smooth and mechanically textured gelfilled prosthesis. They do not seem to be associated with an increased risk of complications or morbidity. The authors also concluded that the capsular contracture after all types of breast surgery is significantly lower for polyurethane foam coated implants than for smooth or textured implants. This benefit persists for a long time, at least ten years after implant placement.

\section{Implant microdamage}

Brody, in his work, suggests that it is the textured surface of the implant that causes chronic trauma due to friction with the surrounding breast tissues, which can lead to neoplastic transformation [35]. Clemens M. also mentions recurrent capsule injury as a possible risk factor for BIA-ALCL, but these observations have not been confirmed in formal epidemiological studies [36]. In the work of Kaartinen I. et al. [37], we find a hypothesis about the development of BIA-ALCL as a result of repeated injuries caused by the interaction between the rough surface of the implant and the inner layer of its capsule. In general, relationships between injuries and tumorigenesis related to various organs have been shown in many works. Lauren A. Wise et al. [38] in a study conducted among African American women 
found a positive relationship between being a victim of physical abuse in adulthood and the occurrence of breast cancer. The mechanism that would probably affect the occurrence of breast cancer in injured women is the chronic activation of the hypothalamic-pituitary-adrenal axis, which affects ovarian function and biosynthesis of steroid hormones involved in the etiology of breast cancer. In their pilot study, Rigby J. et al. [39] report that a causal relationship between physical trauma and breast cancer is likely. However, there is no reason to believe that trauma enhances mutagenesis. It is difficult to imagine how a single episode of injury can lead to a significant increase in cancer risk in the short term.

Injury can simply disrupt blood supply, release stimulating cytokines, or interfere with areas where ductal cancer exists in situ. This can accelerate the growth and timing of clinical signs of a tumor. Kuraishy A. et al. [40] report that many cancers develop in response to chronic tissue damage resulting in cell death, which increases the cancer potential of neighboring cells. Chronic tissue damage and inflammation have long been suspected of their ability to promote the development and progression of cancer, but only recently have these theories been supported by research on mouse models. Importantly, the experimental evidence obtained in mice is strongly supported by the analysis of clinical and epidemiological data in humans.

\section{Discussion}

Breast implant-associated anaplastic large target lymphoma (BIA-ALCL) has been described in the scientific literature for 20 years. In 2011, the FDA (US Food and Drug Administration) officially issued a warning that breast implants increase the risk of its occurrence [41]. The disease occurs in women after breast augmentation for aesthetic reasons and after repair surgery due to the pathology of the mammary gland. The change in surgical techniques and patient selection methods over years, as well patient monitoring strategies, may also be a reason for more widespread occurrence of this disease in certain time periods. So far, none of the theories have been officially recognized as the dominant etiological factors affecting the development of BIA-ALCL. However, it must be admitted that each of them has its logical justification and they are likely to coexist, ultimately leading to the development of BIA-ALCL. Genetic mutations can be the cause of BIA-ALCL as well as of any other affliction. They are an etiological factor mentioned in many diseases - as examined or presumed. On April 14, 2003, a report was published stating the completion of $99 \%$ sequencing of the human genome with $99.99 \%$ accuracy. However, the path to a thorough understanding of the gene mutations responsible for individual disease entities is still far away - the number of possible combinations is innumerable. In addition, it requires time and considerable financial outlays. In turn, biofilm or cutaneous physiological flora, as is commonly known in pathological conditions, ceases to be an ally of the human body. It can become a cause of infection of the surgical site and lead to the development of a chronic inflammatory process. Infection of the surgical site with skin physiological flora is a problem that increases the cost of therapy and harms the final result of surgical treatment. It is a very problematic issue for treatment teams. Despite the implementation of better and better prophylaxis methods, it is still one of the most common complications of surgical treatment. The incidence of surgical site infection is estimated to be in the range of 2-7\% [42]. As for the surface of the implants, the analyzed literature draws attention to the clear percentage advantage of textured surface implants over smooth surface implants - it was recognized that those with a large surface and texture carry the most significant relationship with BIA-ALCL. The theory of the relationship between injury and tumor formation is the least described; however, reports on this topic have been published. Based on general medical knowledge, it can be suspected that the coincidence of the abovementioned factors further increase the risk of developing the disease, and also that some of them follow each other in a timely manner ultimately leading to the development of a tumor of the immune system with a starting point located in the breast implant pouch. Although the phenomenon of this disease is not a new problem, it still requires further research and dissemination of knowledge about it in the medical environment and sensitizing patients after operations using breast implants to the occurrence of symptoms such as swelling, nodules or fluid around the implant, asymmetry breasts, itching, pain or swollen armpit lymph nodes. Patients should be educated that when the abovementioned symptoms occure, they must immediately seek medical consultation. Similarly, before the surgery itself, one should inform about the existence of a disease entity, which is anaplastic large cell lymphoma associated with breast implants. In essence, the patient should be presented with the current state of knowledge, presumed causes, and information about possible treatment should be provided. The patient's consent to the operation must be informed. The growing popularity of the disease does not mean that every woman qualified for breast surgery using the implant is fully aware of the problem, and even more, as a layman, understands the essence of the disease and is aware of the complications arising from it. Meticulously discussion with the patient 
might increase self-awareness and the motivation to report important symptoms. Operated women should know that self-examination is the important method of patient follow-up — probably even more valuable as first-line tool compared to imaging. At the same time, it should be emphasized that the risk of BIA-ALCL should not limit the use of this type of surgery, because this disease is relatively rare. In addition, urging doctors to report and detail BIA-ALCL cases in databases would undoubtedly contribute to a better understanding of the problem. Specialist cooperation in the discussed disease will allow the development of preventive and therapeutic strategies among diagnosed patients. There is a relative lack of prospective randomized studies comparing different types of implants. Probably BIA-ALCL is too rare to be detected this way, but the safety of the clinical approaches is best studied by long-term observation of prospectively collected cohorts, optimally with randomization. For example Peter G. Cordeiro et al. in their publication from 2020 claim that the incidence of BIA-ALCL (1:355 women) in their prospectively followed cohort is higher than previously reported in the literature, if it is about macro-textured breast implants. These results can be helpful for women undergoing breast reconstruction during the choice of implant type [43]. There are some ongoing researches basing on a similar model as for example: Breast Implant-Associated Anaplastic Large Cell Lymphoma (BIA-ALCL) Registry sponsored by The Lymphoma Academic Research Organization. The study is planned to last 13 years and should end in 2032 [44].

\section{Conclusions}

The causes of BIA-ALCL is certainly an interesting issue that requires further attention and research. There are several speculated etiological factors and it is currently impossible to say which of them plays a major role in the pathogenesis of the disease, but they should not be considered separately, as they are likely to coexist, ultimately leading to the development of BIA-ALCL. Activities aimed at better examination of this disease are highly recommended in order to undertake effective methods of preventing its development due to the widespread use of breast implants, especially in oncological surgery, where the possibility of reconstruction of the mammary gland reduces the trauma of women for whom the diagnosis of breast cancer itself is a dramatic event. Moreover emphasis should be placed on early detection of the disease by making patients aware of the possible occurrence of BIA-ALCL and convincing them to perform a thorough and regular breast self-examination which seems to be more valuable than imagine studies in early detection of the disease.

\section{Conflict of interest}

The authors report no conflicts of interest

\section{References}

1. Hedén P, Stark B. [Breast implant-associated anaplastic large cell lymphoma (BIA-ALCL)]. Lakartidningen. 2018; 115, indexed in Pubmed: 29917175

2. Miranda RN, Medeiros LJ, Ferrufino-Schmidt MC, et al. Pioneers of Breast Implant-Associated Anaplastic Large Cell Lymphoma: History from Case Report to Global Recognition. Plast Reconstr Surg. 2019; 143(3S A Review of Breast Implant-Associated Anaplastic Large Cell Lymphoma): 7S-714S, doi: 10.1097/PRS.0000000000005564, indexed in Pubmed: 30817551

3. BIA-ALCL Physician Resources [Internet]. American Society of Plastic Surgeons. https://www. plasticsurgery.org/for-medical-professionals/health-policy/bia-alcl-physician-resources (24.04.2020).

4. Rastogi P, Deva AK, Prince HM. Breast Implant-Associated Anaplastic Large Cell Lymphoma. Curr Hematol Malig Rep. 2018; 13(6): 516-524, doi: 10.1007/s11899-018-0478-2, indexed in Pubmed: 30345474.

5. Collett DJ, Rakhorst H, Lennox P, et al. Current Risk Estimate of Breast Implant-Associated Anaplastic Large Cell Lymphoma in Textured Breast Implants. Plast Reconstr Surg. 2019; 143(3S A Review of Breast Implant-Associated Anaplastic Large Cell Lymphoma): 30S-40S, doi: 10.1097/PRS.0000000000005567, indexed in Pubmed: 30817554.

6. Calobrace MB, Schwartz MR, Zeidler KR, et al. Long-Term Safety of Textured and Smooth Breast Implants. Aesthet Surg J. 2017; 38(1): 38-48, doi: 10.1093/asj/sjx157, indexed in Pubmed: 29040370.

7. Allergan Recalls Natrelle Biocell Textured Breast Implants Due to Risk of BIA-ALCL Cancer [Internet]. US FOOD\&DRUG ADMINISTRATION. https://www.fda.gov/medical-devices/medical-device-recalls/allergan-recalls-natrelle-biocell-textured-breast-implants-due-risk-biaalcl-cancer (24.04.2020)

8. General and Plastic Surgery Devices Panel March 25-26, 2019 Mentor Briefing Package[Internet]. US FOOD\&DRUG ADMINISTRATION. https://www.fda.gov/media/123013/ (24.04.2020).

9. Peters W, Young V, Jerina K. Biomaterials in Plastic Surgery: Breast Implants. Woodhead Publishing 2012: 98

10. Hamdi M. Association Between Breast Implant-Associated Anaplastic Large Cell Lymphoma (BIA-ALCL) Risk and Polyurethane Breast Implants: Clinical Evidence and European Perspective. Aesthet Surg J. 2019; 39(Suppl_1): S49-S54, doi: 10.1093/asj/sjy328, indexed in Pubmed: 30715171

11. Magnusson M, Beath $K$, Cooter R, et al. The Epidemiology of Breast Implant-Associated Anaplastic Large Cell Lymphoma in Australia and New Zealand Confirms the Highest Risk for Grade 4 Surface Breast Implants. Plast Reconstr Surg. 2019; 143(5): 1285-1292, doi: 10.1097/PRS.0000000000005500, indexed in Pubmed: 30789476.

12. Blombery $P$, Thompson $E R$, Jones $K$, et al. Whole exome sequencing reveals activating JAK1 and STAT3 mutations in breast implant-associated anaplastic large cell lymphoma anaplastic large cell lymphoma. Haematologica. 2016; 101(9): e387-e390, doi: 10.3324/haematol.2016.146118, indexed in Pubmed: 27198716.

13. O'Shea JJ, Schwartz DM, Villarino AV, et al. The JAK-STAT pathway: impact on human disease and therapeutic intervention. Annu Rev Med. 2015; 66: 311-328, doi: 10.1146/annurev-med-051113-024537, indexed in Pubmed: 25587654

14. Thomas SJ, Snowden JA, Zeidler MP, et al. The role of JAK/STAT signalling in the pathogenesis, prognosis and treatment of solid tumours. $\mathrm{Br}$ J Cancer. 2015; 113(3): 365-371, doi: 10.1038/bjc.2015.233, indexed in Pubmed: 26151455

15. Oishi N, Miranda RN, Feldman AL. Genetics of Breast Implant-Associated Anaplastic Large Cell Lymphoma (BIA-ALCL). Aesthet Surg J. 2019; 39(Suppl_1): S14-S20, doi: 10.1093/asj/sjy311, indexed in Pubmed: $307151 \overline{69}$.

16. Gristina AG. Biomaterial-centered infection: microbial adhesion versus tissue integration. Science. 1987; 237(4822): 1588-1595, doi: 10.1126/science.3629258, indexed in Pubmed: 3629258.

17. Chagnot $C$, Zorgani MA, Astruc T, et al. Proteinaceous determinants of surface colonization in bacteria: bacterial adhesion and biofilm formation from a protein secretion perspective. Front Microbiol. 2013; 4: 303, doi: 10.3389/fmicb.2013.00303, indexed in Pubmed: 24133488 . 
18. Habimana $\mathrm{O}$, Semião A, Casey $\mathrm{E}$. The role of cell-surface interactions in bacterial initial adhesion and consequent biofilm formation on nanofiltration/reverse osmosis membranes. Journal of Membrane Science. 2014; 454: 82-96, doi: 10.1016/j.memsci.2013.11.043.

19. Rochford ETJ, Richards RG, Moriarty TF. Influence of material on the development of device-associated infections. Clin Microbiol Infect. 2012; 18(12): 1162-1167, doi: 10.1111/j.1469-0691.2012.04002.x indexed in Pubmed: 22925523.

20. Tieszer C, Reid G, Denstedt J. Conditioning film deposition on uretera stents after implantation. J Urol. 1998; 160(3 Pt 1): 876-881, doi 10.1097/00005392-199809010-00081, indexed in Pubmed: 9720580.

21. Costerton JW, Montanaro L, Arciola CR. Biofilm in implant infections: its production and regulation. Int J Artif Organs. 2005; 28(11): 1062-1068 doi: 10.1177/039139880502801103, indexed in Pubmed: 16353112.

22. Jacombs A, Tahir S, Hu H, et al. In vitro and in vivo investigation of the influence of implant surface on the formation of bacterial biofilm in mammary implants. Plast Reconstr Surg. 2014; 133(4): 471e-480e doi: 10.1097/PRS.0000000000000020, indexed in Pubmed: 24675200

23. $\mathrm{Hu} \mathrm{H}$, Jacombs A, Vickery $\mathrm{K}$, et al. Chronic biofilm infection in breas implants is associated with an increased T-cell lymphocytic infiltrate: implications for breast implant-associated lymphoma. Plast Reconst Surg. 2015; 135(2): 319-329, doi: 10.1097/PRS.0000000000000886, indexed in Pubmed: 25383716.

24. $\mathrm{Hu} \mathrm{H}$, Johani $\mathrm{K}$, Almatroudi $\mathrm{A}$, et al. Bacterial Biofilm Infection Detected in Breast Implant-Associated Anaplastic Large-Cel Lymphoma. Plast Reconstr Surg. 2016; 137(6): 1659-1669, doi 10.1097/PRS.0000000000002010, indexed in Pubmed: 26890506.

25. Clemens MW, DeCoster RC, Fairchild B, et al. Finding Consensus After Two Decades of Breast Implant-Associated Anaplastic Large Cell Lymphoma. Semin Plast Surg. 2019; 33(4): 270-278, doi: 10.1055/s0039-1696998, indexed in Pubmed: 31632211.

26. Sorotos M, Longo B, Amorosi V, et al. Macrotextured Breast Implants with Defined Steps to Minimize Bacterial Contamination around the Device: Experience in 42,000 Implants. Plast Reconstr Surg. 2018 142(3): 412e-413e, doi: 10.1097/PRS.0000000000004654, indexed in Pubmed: 29965912.

27. Ryan MP, Adley CC. The antibiotic susceptibility of water-based bacteria Ralstonia pickettii and Ralstonia insidiosa. J Med Microbiol. 2013; 62(Pt 7): 1025-1031, doi: 10.1099/jmm.0.054759-0, indexed in Pubmed: 23579396.

28. Wee AT, Morrey BF, Sanchez-Sotelo J. The fate of elbows with unexpected positive intraoperative cultures during revision elbow arthroplasty. J Bone Joint Surg Am. 2013; 95(2): 109-116, doi: 10.2106/JBJS.K.00121, indexed in Pubmed: 23235940

29. Ryan MP, Adley CC. Ralstonia spp.: emerging global opportunistic pathogens. Eur J Clin Microbiol Infect Dis. 2014; 33(3): 291-304, doi: 10.1007/s10096-013-1975-9, indexed in Pubmed: 24057141.

30. Coussens L, Werb Z. Inflammation and cancer. Nature. 2002 420(6917): 860-867, doi: 10.1038/nature01322.
31. Stefanko E, Wróbel T. Etiopatogeneza infekcyjna chłoniaków. Hematol. 2010(1): 288-295

32. Kadin ME, Deva A, Xu H, et al. Biomarkers Provide Clues to Early Events in the Pathogenesis of Breast Implant-Associated Anaplastic Large Cell Lymphoma. Aesthet Surg J. 2016; 36(7): 773-781, doi: 10.1093/asj/sjw023, indexed in Pubmed: 26979456

33. Bizjak M, Selmi C, Praprotnik S, et al. Silicone implants and lymphoma: The role of inflammation. J Autoimmun. 2015; 65: 64-73, doi: 10.1016/j. jaut.2015.08.009, indexed in Pubmed: 26330346.

34. Handel N, Gutierrez J. Long-term safety and efficacy of polyurethane foam-covered breast implants. Aesthet Surg J. 2006: 26(3) : 265-274, doi: 10.1016/j.asj.2006.04.001, indexed in Pubmed: 19338905

35. Brody GS. The Case against Biofilm as the Primary Initiator of Breast Implant-Associated Anaplastic Large Cell Lymphoma. Plast Reconstr Surg. 2016; 137(4): 766e-767e, doi: 10.1097/01. prs.0000480003.80422.03, indexed in Pubmed: 26809044.

36. Clemens MW, Nava MB, Rocco N, et al. Understanding rare adverse sequelae of breast implants: anaplastic large-cell lymphoma, late seromas, and double capsules. Gland Surg. 2017; 6(2): 169-184, doi: 10.21037/gs.2016.11.03, indexed in Pubmed: 28497021.

37. Kaartinen I, Sunela K, Alanko J, et al. Breast implant-associated anaplastic large cell lymphoma - From diagnosis to treatment. Eur $\mathrm{J}$ Surg Oncol. 2017; 43(8): 1385-1392, doi: 10.1016/j.ejso.2017.05.021, indexed in Pubmed: 28625797

38. Wise LA, Palmer JR, Boggs DA, et al. Abuse victimization and risk of breast cancer in the Black Women's Health Study [corrected]. Cancer Causes Control. 2011; 22(4): 659-669, doi: 10.1007/s10552-011-97383 , indexed in Pubmed: 21327459.

39. Rigby JE, Morris JA, Lavelle J, et al. Can physical trauma cause breast cancer? Eur J Cancer Prev. 2002; 11(3): 307-311, doi: 10.1097/00008469-200206000-00014, indexed in Pubmed: 12131664

40. Kuraishy A, Karin M, Grivennikov SI. Tumor promotion via injury- and death-induced inflammation. Immunity. 2011; 35(4): 467-477, doi: 10.1016/j.immuni.2011.09.006, indexed in Pubmed: 22035839

41. Center for Devices and Radiological Health [Internet]. U.S. Food and Drug Administration. Anaplastic large cell lymphoma (ALCL) in women with breast implants: preliminary FDA findings and analysis. http://www. fda.gov/downloads/MedicalDevices/ProductsandMedicalProcedures/Implant- sandProsthetics/Breastlmplants/UCM240003 (24.04.2020).

42. Pupka D, Sawicki T, Sikora J, et al. Zakażenie miejsca operowanego - postępowanie. Chirurgia po Dyplomie. 2019; 02.

43. Cordeiro PG, Ghione P, Ni A, et al. Risk of breast implant associated anaplastic large cell lymphoma (BIA-ALCL) in a cohort of 3546 women prospectively followed long term after reconstruction with textured breast implants. J Plast Reconstr Aesthet Surg. 2020; 73(5): 841-846, doi: 10.1016/j.bjps.2019.11.064, indexed in Pubmed: 32008941.

44. Breast Implant-associated Anaplastic Large Cell Lymphoma (BIA-ALCL) Registry. ClinicalTrials.gov. https://clinicaltrials. gov/ct2/show/NCT04220970 (24.10.2020). 